\title{
Reuben Lasker
}

This book is dedicated to Reuben Lasker, an eminent scientist who worked in the Southern California Bight. His investigations in the physiological ecology of marine organisms began as a Sverdrup Post-Doctoral Fellow at Scripps Institution of Oceanography (SIO) in 1956. He was educated at Stanford where he received his doctorate under the tutelage of Arthur C. Giese. At his untimely death in 1988, Reuben was leader of the Coastal Fisheries Resources Division of the Southwest Fisheries Science Center of the National Marine Fisheries Service on the campus of SIO, with a staff of about 50 scientists and technicians under his supervision. He was also involved in the preparation of this book as a member of the Quality Review Board. Reuben was active in graduate education and for 15 years held an appointment as Adjunct Professor of Marine Biology at SIO.

Reuben was an especially gregarious scientist, and his knowledge and warm support of marine science attracted a long list of collaborators during his career. One example of this is that in a bibliography prepared for the MMS project, 260 of the citations were produced by Reuben and 50 of his associates. He adopted as colleagues children of his fellow staff associates, local high school students, and National Academy of Science/National Research Council Senior Post-Doctoral Fellows. Reuben operated in all arenas of marine science: experimental laboratory work, satel-

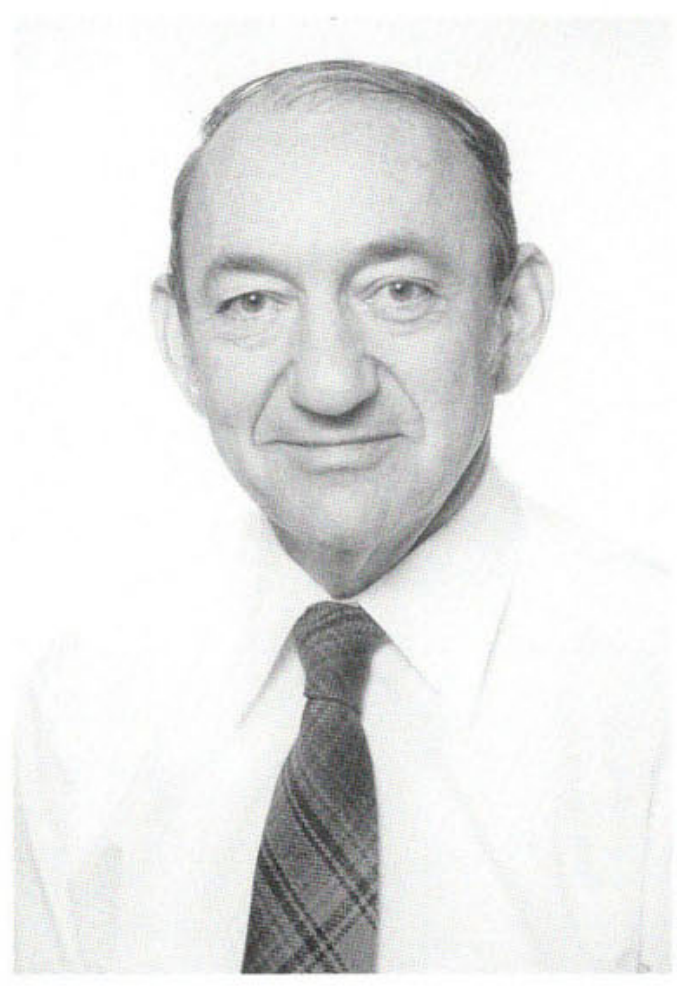

lite remote sensing, work at sea, and mathematical modeling.

Reuben Lasker received much recognition for his work: the Meritorious Service Award of the U.S. Department of the Interior, 1970; the Distinguished Service Award of the U.S. Department of Commerce, 1974; the Huntsman Medal for Excellence in Biological Oceanography from the Canadian Government 
Bedford Institute of Oceanography; and the posthumous Outstanding Achievement Award of the American Institute of Fishery Research Biologists, 1988.

It is sufficient to say here that future studies of the ecology of the SCB, and similar marine habitats around the world, will be affected by this gregarious scientist, his scientific accom- plishments, and his influence on his students, friends, and colleagues.

Paul E. Smith

NOAA/NMFS Southwest Fisheries Science Center

La Jolla, California 